\title{
HUBUNGAN KORELASI ANTARA TRADISI BUDAYA TIONGHOA DENGAN AGAMA BUDDHA
}

\author{
Kabul Praptiyono \\ STAB Maha Prajna \\ e-mail: kabulmetta@gmail.com
}

\begin{abstract}
This study examines to find out the correlation between the Chinese tradition and Buddhism. This research was conducted using a qualitative model using the library study approach, data collection was done by taking literature and sources about Chinese cultural traditions and Buddhist literature. The stages of conducting research are the beginning of the planning, drafting and completion stages. The results obtained from this study are that Chinese cultural traditions are very competent, complex and have very high religious values, where the cultural traditions of Buddhism all forms lead to the attainment of holiness. One of the Buddhist traditions that has the same value with the Chinese tradition is in terms of ancestral puja which is often in Buddhism in the class with the name Ulambana.
\end{abstract}

Keywords: Correlation, Tradition, Chinese, Buddhism, Library Studies

\begin{abstract}
Abstrak
Penelitian ini mengkaji untuk mengetahui hubungan korelasi antara tradisi budaya tionghoa dengan agama buddha. penelitian ini dilakukan dengan menggunakan model kualitatif dengan menggunakan pendekatan studi kepustakaan, pengambilan data dilakukan dengan mengambil literatur serta sumbersumber tentang tradisi budaya tionghoa serta literatur buddhis. Tahapan pelaksanaan penelitian yaitu awal tahap perencanaan, penyusunan, dan penyelesaian. Hasil yang diperoleh dari penelitian ini yaitu tradisi budaya tionghoa sangatlah beraga,, komplek serta mempunyai nilai religius yang sangat tinggi, dimana tradisi budaya agama buddha semua bentuk mengarah kepada pencapaian kesucian. Salah satu tradisi buddhis yang memiliki nilai kesamaan dengan tradisi tionghoa yaitu dalam hal puja leluhur yang sering dalam agama buddha dikelas dengan nama ulambana.
\end{abstract}

Kata Kunci: Korelasi, Tradisi, Tionghoa, Agama Buddha, Studi Pustaka

\section{Pendahuluan}

Sebelum mengenal agama-agama manusia hidup berdasarkan nilai-nilai/ norma yang telah disepakati bersama. Dan jika terjadi suatu pelanggaran maka dikenai sangsi sesuai tingkat pelanggarannya. Cara hidup dengan mewarisi adat kebiasaan turun-temurun dari nenek moyang seperti ini kemudian hari dikenal dengan tradisi budaya.
Tradisi budaya suatu bangsa dapat dipakai sebagai tolok ukur kemajuan suatu peradaban. Hal itu dapat dilihat dari peninggalan-peninggalan yang ada, seperti: Karya seni; benda-benda purbakala, bentuk bangunan, adat-istiadat/ tatakrama, sistem kepercayaan dll. Sebagai contoh; bangunan Piramid menunjukan tingkat kemajuan tradisi budaya Mesir dijaman Fir'aun, Borobudur menunjukan tingkat kemajuan tradisi budaya 
Jawa dijaman Smaratungga, Tembok Raksasa( great wall) menunjukan kemajuan tradisi budaya Tionghoa dijaman Dinasti Chin dll.

Nilai tradisi budaya suatu bangsa lebih bersifat lokal dibandingkan dengan Agama Buddha yang universal. Namun demikian tradisi budaya juga syarat dengan niai-nilai yang penting dan berharga, seperti: nilai kemanusiaan, patriotisme, kebersamaan dll. Karena tidak memahami tradisi budaya suatu kelompok tertentu terkadang menjadi pemicu konflik yang mengarah pada perpecahan dan peperangan.

Keberadaan Etnis Tionghoa bagi perkembangan umat Buddha Indonesia amat sangat berarti. Mereka memiliki Tradisi budaya sangat beragam yang kaya akan nilai-nilai moralitas, bakti pada keluarga dan negara. Beberapa tradisi budaya itu diantaranya adalah: Tradisi Tahun Baru Imlek, Tradisi Sembahyang kubur/ leluhur, Tradisi Kau Chung, Tradisi Mandi U-Shi, Kue Bulan, Kue Bak Cang, Festival Naga, Barongsai, Ta Tung / Lauya dll.

Kurangnya pengetahuan keragaman tradisi budaya dilingkungan Tionghoa ini kadang mengaburkan arti religius agama yang mereka anut. Hal itu dapat terjadi diantaranya karena para misionaris berusaha untuk membungkus agama sesuai tatacara tradisi budaya setempat dengan harapan agama yang diwartakan dapat diterima sehingga mempunyai pengikut yang banyak. Hal itu juga terjadi dilingkungan umat Buddha tertentu yang mempunyai pandangan bangga dengan memiliki jemaat yang banyak. Akan tetapi dilain sisi justru alkulturasi tradisi budaya seperti kadang menjadi bumerang bagi kemurnian ajaran agama yang sedang diwartakan.

Kewajiban umat Buddha diantaranya adalah meluruskan pandangan , menginterpretasi tradisi budaya apa saja, terlebih tradisi Tionghoa khususnya agar dapat berada pada posisi yang sebenarnya sehingga lebih terhormat dan mempunyai nilai kebajikan universal yang pada akhirnya akan memberikan kontribusi terhadap kemajuan batin umat Buddha itu sendiri. Sebagai contoh misalnya; Im Lek, periode pergantian tahun masyarakat Tionghoa yang dirayakan cukup meriah ini kedudukannya sama seperti merayakan hari raya agama pada tradisi agama tertentu. Lauya / Ta Thung dianggap Dewa yang dapat melindungi dan mengatasi masalah. Ketika sakit atau mengalami kesulitan .

Karena terjadi alkulturasi antara Buddha Dhamma dengan tradisi budaya Tionghoa maka banyak orang beranggapan bahwa praktek Lauya / Ta Thung adalah produk dan tradisi agama Buddha. Kenyataan yang terjadi dilapangan sebenarnya dalam praktekanya para Lauya/ Ta Thung menggunakan atributatribut yang hampir sama dengan praktek ritual agama Buddha Mahayana khususya, seperti memasang lilin, hio, air dan buah sekalipun terkadang para Lauya ini ada yang menyimpang dalam prakteknya menggunakan daging, arak dan darah. Generalisasi yang tidak tepat seperti ini umat agama lain terkadang memandang sinis terhadap umat Buddha, sekalipun ada umat Buddha yang tidak tahu menahu tentang praktek Lauya.

Buddha Gotama mengkritik semua praktek yang berorentasi pada pamer kekuatan ( ilmu gaib), mengaku telah mencapai tingkat kesucian dll, untuk mencari penghidupan , popularitas dan keuntungan pribadi. Hal-hal seperti itu melanggar Vinaya kebhikkhuanya, bahkan dapat dikeluarkan dari Sangha ( salah satu Parajika). Praktek Lauya dalam kehidupan sehari-hari umumnya bermotivasi menolong bukan untuk mencari keuntungan pribadi tetapi akhir-akhir ini praktek Lauya/ Tathung di ekplorasi orang tertentu untuk tujuan komersial. 
Ekplorasi tradisi budaya berdampak menguntungkan dan sekaligus merugikan. Menguntungkan karena tradisi budaya yang tidak dikenal masyarakat dapat dikenal masyarakat luas. Merugikan karena ekplorasi budaya terkadang mengabaikan nilai-nilai religius yang terkandung didalamnya sehingga terkesan biasa-biasa saja. Tidak mendasar dan hanya mempunyai nilai estetika belaka.

Dampak buruk lainya adalah generasi muda menilai bahwa tradisi budaya itu hanya bersifat tahayul, dongeng, tidak mendasar dalam kehidupan sehari-hari dan tidak bermanfaat sehingga mengurangi minat akan memahmi makna sesunggunya dari tradisi budaya tersebut. Disisi lain karena tidak memahami Dhamma banyak umat Buddha sekalipun berpendidikan tinggi, kaya dan berkecukupan secara materi ketika menghadapi masalah yang pelik mengenai rumah tangga, pekerjaan, kesehatan, asmara, dan keberuntungan pergi ke Paranormal, Dukun atau Lauya untuk meminta tolong.

Dasar keyakinan akan sangat mempengaruhi nilai tradisi dan budaya suatu bangsa. Orang Tionghoa memiliki dasar keyakinan yang kuat terhadap keseimbangan antara alam dan manusia, keseimbangan manusia dengan dunia roh atau keabadian. Konsep keseimbangan ini melahirkan berbagai disiplin ilmu dikemudian hari. Keseimbangan alam dengan manusia melahirkan; ilmu perbintangan, iklim dan cuaca. Ilmu keseimbangan energi kedokteran melahirkan teori Yin-Yang.

Dasar-dasar keyakinan ini juga mempengaruhi sikap hidup orang Tionghoa dalam kehidupan sehari-hari, seperti: bakti pada leluhur, keluarga, nusa dan bangsa yang dikemudian hari menjadi tradisi Sembahyang kubur, Mandi U-shi, Legenda Bak Cang, Kue Bulan dll. Beberapa dasar keyakinan Orang Tionghoa itu adalah 1) Cara memandang kehidupan bagi orang Tionghoa terdapat beberapa versi tergantung latar belakang kebudayaan yang dianutnya. Namun pada umumnya masih memegang teguh nilai-nilai tradisional dari para leluhurnya yang tercemin dalam Konfusius dan Lao Tze. Sebagian mengikuti tradisi Buddha, Kristen atau Islam. Tradisi Konfusius dianggap mewakili tradisi budaya Tionghoa yang tertua sebelum Tao (Lao Tze) maupun Buddha. Iksan Tanggok ( 2007 ) dalam bukunya, Mengenal lebih dekat Agama Konghucu memaparkan bahwa:

"Orang Tionghoal Tiongkok karena latar belakangnya adalah Petani maka alam adalah sahabat yang terdekat dan utama. Oleh karenanya mereka melakukan pemujaan terhadap alam. Langit, bumi, matahari dan bintang yang dianggapnya sebagai sumber kekuatan gaib (Adikodrati) yang utama bagi kehidupan."

Dalam hal ini jika manusia harmonis dengan alam maka manusia akan mengalami kemakmuran sesuai dengan hukum sebab akibat. Pada konsep awal ini tidak dikenal adanya Causa Prima sebagai titik puncak kebaktian manusia. Dalam Tao Te Ching pasal 42 proses hidup Taoist; Tao melahirkan satu, satu melahirkan dua, dua melahirkan tiga dan tiga melahirkan semua bentuk kehidupan. Thian adalah bapak dan Tee adalah ibu. Yang jernih membubung ke atas menjadi Thian (langit) yang keruh mengendap menjadi Tee (bumi),....makluk atau Jin/ manusia berkiprah diantara keduaya. 2) Dewa - dewi dalam mitologi Tionghoa adalah mewakili hasrat keinginan manusia. Jika manusia dianggap telah memiliki prasyarat tertentu, segala bentuk keinginanya akan dikabulkan para Dewa. Mereka yang sempurna prilakunya, luhur budi pekertinya, bermartabat, banyak melakukan perbuatan baik, tekun dalam mengolah batin (xiulian) maka akan mendapat imbalan kehidupan abadi sebagai Dewa. 
Delapan dewa (Pat Shien) itu adalah: 1) Tee Guai Li sebagai Dewa Kemiskinan, 2) Han Xiangzi -Dewa Kekayaan , 3) Zhangli Quan - Dewa Kedudukan, 4) Coa Guo Jiu - Dewa Kejelatan, 5) Zhang Guo Lao - Dewa Usia Muda, 6) Lan Caihe-Dewa Usia Tua, 7) Lu Dong bin-Dewa Keperkasaan, 8) He Xiang U -Dewa Kelembutan. (Majalah Tridharma edisi Juni 2001)

Para Dewa ini diutus oleh Kaisar Langit (Yik Huang Shang Ti) dan di akhir tahun menjelang tahun baru mereka menghadap Kaisar Langgit untuk melaporkan kewajibannya dialam manusia. Sebagai apresiasi baktinya terhadap para dewa yang dianggap telah berjasa dalam mengabulkan keinginannya maka orang Tionghoa melakukan banyak pemujaan terhadap para dewa (polyteisme). Mereka mempersembahkan makanan, minuman, bunga, hio, lilin yang terbaik dengan harapan para dewa menjadi senang dan melaporkan hal-hal yang baik kepada Kaisar Langit. 3) Manusia mempunyai keterikatan lahir batin yang kuat terhadap keluarganya. Tidak hanya pada orang Tionghoa kepecayaan dan pemujaan terhadap leluhur dilakuan. Pemujaan terhadap leluhur yang telah tiada dilakukan didepan altar keluarga/ silsilah keluarga. Disini mereka mempersembahkan berbagai makanan kesukaan para mendiang keluarga yang telah meninggal. Adakalanya mereka lakukan dikuburan (ka chi) dengan berziarah (Xao Moh), membersihkan rumput, memberikan sajian makanan dan membakar uang-uangan kertas dll. 4) Hong Sui atau Feng Sui adalah ilmu arsitektur pada masa Tiongkok kuno, secara harafiah Hong -Sui berarti angin dan air. Ilmu ini membahas berbagai faktor yang menunjang keselarasan bangunan sehingga membawa berkah dan keberuntungan bagi penghuninya. Seperti: bagaimana arah dan letaknya, sirkulasi udara/ energinya, elemen-elemen alami yang mendukung, warna yang dominan dsb. Hong Sui menekankan bahwa manusia harus hidup dalam keseimbang dengan air, angin dan tanah. Jika tidak unsur -unsur ini akan menghambat kemajuan manusia. Sedang Peh Ji (Ba Zi) adalah ilmu ramalan yang peganalisaannya berdasarkan pada tanggal dan jam kelahiran manusia. Prinsip Hong Sui dan Peh Ji adalah pergerakan Pak Kua/ Pat Kwa (Delapan Trigram), perpaduan Yim dan Yang, serta tranformasi U Xing/ Ngo Heng (lima elemen). Prinsip -prinsip perubahan itu termuat dalam kitab I Ching. Kitab ini telah dimuliakan selama ribuan tahun sebagai tuntunan keberhasilan dan sumber kebajikan. Konsep dasar I Ching sendiri telah dikembangkan lebih dari 4000 tahun yang lalu oleh Kaisar Fu Xi / Hok Hie (2953 s.M - 2838 s.M ). Di dapat satu kesimpulan bahwa: semua pergerakan/ perubahan dialam semesta dengan segala isinya berubah mengikuti hukum kesemestaan. 5) Semua filsafat Tiongha didasari prisip dualisme keselarasan alam semesta yang sempurna Yin- Yang. Keduanya saling melengkapi dan menjadi satu kekuatan yang tak tertandingkan. Energi universal yang mengalir diantara bumi dan langit, menaburkan kebahagiaan berlimpah dan kemakmuran dimanapun berada itu disebut Ch'i atau nafas kosmis. (Buletin Tridharma, edisi 03/XXVIII/Mei-Juni 2003)

Lie Sau Fat / XF. Asali dalam bukunya Aneka Budaya Tionghoa Kalimantan Barat sedikitnya menulis ada 14 tradisi budaya orang Tionghoa, seperti 1) Tahun Baru Imlek, Hari Raya Festifal Musim Semi. 2) Naga dalam Legenda, Makluk Tanpa Sayap Bisa Terbang. 3) Seni Budaya permainan Barongsai. 4) Cap Go Meh / Cang Njiat Pan, Yuan Shiau Ciek. 5) Tradisi Mandi U-Shi. 6) Tuan U Ciek, air U-Shi, kue Bak Cang dan Kwe Cot. 7) Legenda Bak Cang, Chiu Yuan penyair yang tersingkirkan. 8)Tradisi sembahyang 
Kuburan. 9) Asal usul dan Makna Ching Ming/ Ceng Beng. 10) Prosesi Pemakamam Tionghoa, 11) Legenda Festival Kue Bulan, 12) Kiet Fun / Adat Perkawinan Tradisional Tionghoa, 13) Uniknya Marga, 14) Tien Chon dll. (Asali,XF, 2007).

Dalam buku Asal-mula Festifal China. PT Elex Media Komputindo.100 Chinese Gods. 1998. Asiapac Books. Banyak menulis adat tradisi budaya Tionghoa. Dan ternyata masih ada tradisi budaya yang belum disebutkan Lie Sau Fat seperti: Legenda Putri Tikus, Kau Cun dan lainya.

Berkaitan dengan Latar Belakang tersebut diatas maka penulis tertarik untuk meneliti dalam skripsi ini dengan judul : KORELASI TRADISI BUDAYA ORANG TIONGHOADENGANAGAMABUDDHA

\section{Metode}

Metode penelitian berbeda dengan prosedur penelitian dan tehnik penelitian. Metode penelitian membicarakan mengenai tatacara penelitian, sedangkan prosedur penelitian membicarakan urutan Kerja penelitian dan tehnik penelitian. Tehnik Penelitian membicarakan alat-alat yang digunakan dalam mengukur atau mengumpulkan data penelitian. Dengan demikian metode penelitian adalah suatu tata cara yang ilmiah untuk mendapatkan data dengan tujuan tertentu melingkupi prosedur dan tehnik penelitian.

Cara Ilmiah berarti kegiatan itu didasarkan pada ciri-ciri keilmuan, yaitu rasional, empiris dan sistimatis. Rasional berarti kegitan penelitian itu dilakukan dengan cara-cara yang masuk akal sehingga terjangkau oleh pemikiran manusia. Empiris berarti, cara-cara yang dapat diamati oleh indera manusia sehingga orang lain dapat mengamati dan mengetahui cara-cara yang digunakan. Sistimatis berarti proses yang digunakan dalam penelitian itu menggunakan langkah-langkah tertentu yang bersifat logis. (Sugiono, 2000).

Kegiatan penelitian dapat dikatakan hampir semua bertolak dari Ilmu Pengetahuan yang sudah ada sebelumnya. Pada semua Ilmu Pengetahuan, Ilmuwan selalu memulai penlitiannya dengan cara mengutip apa-apa yang sudah dikemukakan ahli lain. Peneliti memanfaatkan teori-teori yang ada dibuku atau hasil penelitian lain untuk kepentingan penelitian.

Orang peneliti yang mendalami, mencermati, menelaah dan mengidentifikasi pengetahan yang ada dalam kepustakaan (sumber bacaan, buku-buku refensi atau hasil penelitian lain) untuk menunjang penelitiannya, disebut mengkaji bahan pustaka atau studi kepustakaan (Iqbal Hasan, 2002) Studi kepustakaan (library research) merupakan serangkaian kegiatan yang berkenaan dengan metode pengumpulan data kepustakaan, membaca dan mencatatat serta mengolah bahan penelitiaan (Zed, 2004;3); Kegiatan mendalami, mencermati, mengidentifikasi pengetahuan yang telah ada untuk mengetahui apa yang belum ada (Arikunto, 2000;75); dan menekankan analisis hipotesa ilmiah dengan data-data (Azwar, 2001:5)

Dalam penelitian skripsi analisis Tradisi Budaya Tionghoa menurut agama Buddha, penulis mendalami, mencermati, menelaah dan mengidentfikasi pengetahuan yang ada dalam kepustakaan (sumber bacaan, bukubuku, refrensi atau hasil penelitian lain) untuk menunjang penelitian dengan pendekatan Buddhis. Pemeriksaan keabsahan data bertujuan untuk membuktikan keaslian sumber yang digunakan. Pemeriksaan keabsahan data dilakukan dengan pemeriksaan dan penafsiran data untuk memperoleh hasil sementara menjadi teori substansi dengan menggunakan berbagai metode (Moleong, 2004:247). Data 
yang sah apabila mendemontrasikan nilai yang benar dan menyediakan dasar agar dapat diterapkan.

Tujuan Studi kepustakaan adalah membaca kritis segala kepustakaan dengan: (1) meneliti masalah-masalah penyusunan yang rumit dan mengekspresikan semua bahan dari berbagai macam sumber, (2) mengadakan seleksi dari berbagai bahan yang mengandung sudut pandang berbeda-beda dengan memilih, menimbang, mengolah dan menyusun kembali bahan-bahan kepustakaan ke dalam bentuk akhir yang dapat diterima oleh semua pembaca dari segala lapisan masyarakat (Keraf, 1984:165-166).

Peneliti menggunakan metode kepustakaan dengan pertimbangan, (a) peneliti berhadapan dengan teks (nash) atau data angka, (b) data pustaka bersifat "siap pakai" (ready made), yaitu peneliti berhadapan langsung dengan sumber dan bahan yang tersedia di perpustakaan, (c) peneliti berhadapan dengan data statik (Zed, 2004:4-5). Peneliti berhadapan langsung dengan data untuk mendeskripsikan masalah yang dianslisa, dengan harapan penelitian analisis Tradisi Budya orang Tionghoa menurut agama Buddha menghasilkan informasi dalam bentuk deskripsi yang jelas dan valit. Agar dapat memberikan data yang valid harus memenuhi minimal tiga kriteria. Ketiga kriteria itu adalah sebagai berikut: a) Relevasi, Relevansi berkenaan dengan kecocokan antara hal-hal yang diteliti dengan teori-teori yang diketemukan. Makin cocok antara hal-hal yang diteliti dengan teoriteori yang diketemuan maka semakin baik studi kepustakaan tersebut. b) Kelengkapan, Kelengkapan berkenaan dengan banyaknya kepustakaan yang dibaca. Semakin banyak kepustakaan yang dibaca atau diketemukan berarti semakin lengkap kepustakaan dan semakin valit studi kepustakaan tersebut.

c) Kemutakhira, Kemutakhiran berkenaan dengan dimensi waktu (baru atau lama) kepustakaan yang digunakan, dan semakin mutakhir kepustakaan yang digunakan, serta semakin baik studi kepustakaan tersebut.

Penulis mengutip secara utuh atau sebagian intisari dibuku-buku refrensi tersebut yang sesuai dengan pokok-pokok materi penulisan penelitian. Dengan metode penelitian kajian pustaka (library research) ini diharapkan akan terungkap jawaban dari masalah penelitian mengenai Tradisi Budaya Orang Tionghoa Menurut Agama Buddha.

Mengenai prosedur atau tahapan pelaksanaan kegiatan penelitian ini dilakuan melalui tiga tahap sebagai berikut ini: Tahap pertama merencanakan judul yang akan di angkat dalam judul penelitian. Tahap kedua proses penulisan dan penyususunan peneliti memakai empat tahap seperti; persiapan alat, bibiliografi, mengorganisai waktu, membaca dan pencatatan a) Perlengkapan yang disiapkan berupa alat-alat tulis, dimaksudkan untuk mencatat data-data yang telah diperoleh seperti pencatatan bibliografi kerja yang sesuai dengan dengan telaah Korelasi Tradisi budaya Tionghoa dan agama Buddhia, mencatat pertanyaan penelitian, orangorang yang akan dihubungi untuk membantu informasi dan meminjam buku perpustakaan serta time schedule. b) Pengorganisasian waktu dilakukan dengan mempertimbangkan sejauh mana kemampuan penulis, situasional dan keajegan dalam membaca dan mencatat sumber-sumber bacaan kepustakaan. Menentukan waktu keperpustakaan, konsultasi dengan pembimbing, dan menghubungi informan yang dapat membantu. Penyusunan schedule. Dilakukan secara releksasi dengan mempertimbangkan kemampuan fisik manusiawi, tetapi tidak menyia-siakan waktu yang singkat (Zed, 2004; 21-22). c) Membaca dan mencatat bahan penelitian merupakan bagian penting dalam studi kepustakaan. Melalui membaca dan mencatat 
dapat diperoleh keterangan dan latar belakang masalah yang diteliti (Nazir, 1988:123)

Pendapat Saukah, 1992 yang dikutip Sholeh yang penulis gunakan terdapat enam langkah dalam mencatat dan membaca bahan penelitian yaitu: (1) Perenungan awal dengan membaca kritis sumber primer dan sekunder, serta menghubungkan dengan masalah yang diteliti, (2) membaca bagian kata pengantar dan pendahuluan untuk mengetahui isi dan kesesuaian dengan masalah yang diteliti, (3) pengajuan pertanyaan untuk memperjelas arah penelitian, (4) mencatat informasi bibliografi, (5) menjaga interaksi pikiran dengan bahan yang sedang dibaca, (6) mengulang kembali hal-hal yang telah dibaca dan dicatat. Sedangkan hal-hal yang dicatat adalah: ekstrak kata-demi-kata, ringkasan, referensi, deskriptif, dan reflektif. (Sholeh, 1993:63).

Enam langkah tersebut mempermudah penulis dalam mengumpulkan sumber primer dan sekunder yang mendukung penelitian analisis Perbandingan Cara meningkatkan kesehatan tradisi Tiongkok dan agama Buddha.

Tahap ketiga penyajian studi kepustakaan dilakukan dengan dua macam cara, yaitu kutipan langsung dan kutipan tidak langsung. a) Kutipan langsung, yaitu jika dalam menuangkan hasil kajian penulis memindahkan hasil karya orang lain masih dalam bentuk aslinya, baik secara utuh atau sebagian. b) Kutipan tidak langsung, yaitu jika dalam menuangkan hasil kajian, peneliti terlebih dahulu meramu atau mengambil intisari dari berbagai sumber kajian. (Iqbal Hasan, 2000: 46)

Setelah dipelajari, penulis memindahkan hasil karya orang lain masih dalam bentuk aslinya, baik utuh maupun sebagian (kutipan langsung) atau dalam menuangkan hasil kajian penulis terlebih dahulu meramu (membuat sintesa) atau mengambil intisari dari beberapa sumber kajian.

Analisis data adalah proses mengorganisasikan dan mengurutkan data ke dalam pola, kategori, dan satuan uraian dasar sehingga ditemukan tema serta dapat dirumuskan hipotesa kerja seperti yang disarankan oleh data (Moleong, 2004:280). Proses analisis studi komparatif analisis Korelasi TradisiBudaya Orang Tionghoa danTradidsi Budaya Buddhis melalui bebrapa tahap yaitu: 1) Pengumpulan data dilakukan dengan mengumpulkan bukubuku yang ada hubungannya dengan judul skripsi. Selama pengumpulan data penulis menentukan: (1) tujuan tentang data yang diperoleh, (2) menyiapkan buku dan alat perlengkapan, (3) membaca buku yang akan diberikan tanda-tanda tertentu untuk keperluan tuntunan, (4) mengutip kalimat dan mengkaji makna yang terdapat pada kalimat, dengan mempertimbangkan kontek dan menghubungkan antara pernyataan satu dengan pernyataan lain, (5) menumbuhkan ide tertentu pada kartu kutipan serta menempatkan pada kelompoknya. 2) Pada tahap sesudah data terkumpul penulis mengidentifikasikan dan mengorganisasikan data-data yang terkumpul, mensintesis antara pertanyaan yang satu dengan pertanyaan yang laindan analisis diuraikan dalam bentuk pola, tema dan uraian. 3) Pengolahan data dengan cara menganalisa buku-buku dengan menghimpun beberapa sumber yang ada hubungannya dengan judul skripsi untuk mendapatkan data yang relevan. 4) Penulis memberikan gambaran berupa tafsiran atau interpretasi terhadap data tentang perbandingan cara menciptakan kesehatan tradisi Tiongkok dan agama Buddha. 5) Penulis membuat kesimpulan -kesimpulan berkaitan dengan hipotes Yaitu dduga bahwa terdapat beberapa kesamaan dan perbedaan cara meningkatkan kesehatan. 


\section{Hasil}

Masyarakat Tionghoa yang sebagian besar memeluk agama Buddha di Indonesia ada sebagian yang sudah meninggalkan tradisi budaya, tetapi sebagian besar masih melaksanakannya dalam kehidupan seharihari. Sang Buddha tidak melarang umatnya untuk meninggalkan tradisi budaya tetapi menganjurkan untuk menerimanya dan hidup dengan tradisi tersebut apabila tradisi itu membawa manfaat dan kemajuan dalam kehidupannya.

Demikian juga, orang Tionghoa yang memeluk agama Buddha dapat menjalankan tradisi yang sudah turun-temurun dengan dilandasi kebijaksanaan. Tradisi-budaya tersebut di antaranya adalah tradisi pemujaan terhadap para leluhur dan para Dewa, Festival Musim Semi, Praktek Cenayang Lauya/ Ta Thung pada acara Cap Go Meh, Barongsai, Tradisi Mandi U-Shi, Tuan U Ciek, air U-Shi, kue Bak Cang dan Kwe Cot, Tradisi sembahyang Kuburan, Ceng Beng, Legenda Festival Kue Bulan, Kiet Fun / Adat Perkawinan Tradisional Tionghoa, Tien Chon yang sudah berlangsung sejak dahulu kala.

\section{Tradisi puja}

Memanggil Dewa ( Devata Aradhana) dalam tradisi Tionghoa adalah untuk meberi penghormatan, sekaligus menunjukan rasa bakti kepada para dewa atas perlindungan dan bimbingannya. Tepai dalam tradisi Buddha adalah mengajak para Dewa turut serta dalam mendengarkan dan merenungkan kembali Dhamma Buddha lewat Pembacaan Paritta.

"Semoga para dewa disegenap alam datang, kesini mendengarkan Ajaran Kebenaran Buddha, Raja para bijaksana, yang membimbing kesurga dan kebebasan. Datanglah para dewa yang bersemayam disurga, yang berada ditingkat alam napsu ataupun ditingkat alam berbentuk; juga dewa bumi yang bersemayam di vimana( tempat menyenangkan/ bersemayam para dewa) atau dipuncak gunung, dijurang, diangkasa, dipulau, dikota,didesa, dipepohonan,dihutan belukar, disekitar rumah atau disawah-sawahladang; juga para yakkha, gandhabba, dan naga yang bersemyam diperairan, daratan atau pun diperbukitan. Silahkan mereka yang berada disekitar ini mendengarkan sabda Buddha, Raja para bijaksanawan, seperti beikut ini. Sekarang tiba saatnya mendengarkan Dhamma (3X)

Jadi tradisi puja adalah untuk melatih kualitas batin seseorang bukan untuk meminta berkah. Puja dapat berupa materi ( amise puja) seperti persembahan Lilin, Hio/dupa, Air, Bunga, Buah-buahan dan makanan. Dapat juga berupa perbuatan/ prilaku ( patipati puja).

\section{Perayaan Tahun Baru}

Perayaan Pergantian tahun telah dirayakan sejak dulu kala, untuk menandakan pergantian tahun. Makna relegius dari perayaan ini adalah untuk intropeksi diri, mengevalusi perjalanan hidup selama setahun. Mana yang perlu ditingkatkan dan mana yang harus dihilangkan.

\section{Praktek Cenayang ( Ta Thung/ Lok Thung)}

Kesurupan / terpengaruh makluk halus ( Ta Thung) oleh penghuni alam rendah seperti; petta, asura dan yakkha, ada kalanya meminta sesuatu yang melanggar kesusilaan. Yakkha, makluk halus jahat yang terkenal sakti dalam usahanya memenuhi keinginan,seperti; makan, minum sering dengan cara-cara memaksa/ mempengaruhi orang yang kesadarannya lemah.

Terdapat duapuluh lima kondisi yang menyebabkan lemahnya kesadaran, seperti;1) kemarahan, 2)permusuhan, 3)kemunafikan, 4) kecongkakan, 5)keirihatian, 6)ketamakan, 7) kebohongan, 8)pengkhianatan, 9)keras kepala, 10)suka melawan, 11)kesombongan, 12)suka 
pujian, 13)pandangan yang berlebihan 14) ketidakpedulian 15)keengganan, 16)teman yang jahat, 17)rasa ngantuk dan malas, 18) obyek yang terlihat, 19)suara, 20)bau, 21)cita rasa, 22)sensasi sentuhan, 23)rasa lapar, 24) rasa haus, 25 ketidak puasan.

Dalam praktek Ta Thung, masayarakat Tradisional Tionghoa dipakai untuk meramaikan suasana Cap Go Meh dan membersihkan suasana dari roh-roh jahat, hantu, yakkha dan peta. Ada kalanya untuk konsultasi usaha dan rumah tangga.

\section{Berendam di sungai}

Untuk membersihkan diri dari dosa, karma buruk, mendapatkan berkah dan umur panjang harus diimbangi dengan tekad dan kemauan yang kuat. Kepercayaan yang membuta praktek berendam di sungai pernah dikritik Buddha. Hendaklah manusia berendam dalam sila untu mencapai kesempurnaan hidup.

\section{Rasa bakti}

Bakti adalah salah satu sifat mulia yang harus dikembangka oleh mereka yang ingin mencapai kesempurnaan (Jalan Bodhisatva). Bakti pada orang tua berarti melayani dan memenuhi kebutuhan hidupnya. Juga memberikan penghormatan dan sesajian jika telah meninggal dunia. Meneladani semangat dan perjuangan para pahlawan demi kemerdekaan, kesejahteraandan kemakmuran. Terhadap mereka itu kita harus memberi penghormatan yang tulus.

Apapun mereknya jika memenuhi kedelapan hal berikut ini dapat dipraktekan sebagai pedoman hidup. Delapan hal itu adalah bertujuan sebagai berikut ini: 1) mengurangi rangsanagan indera dan pikiran. 2) membebaskan diri dari dukkha/ penderitaan. 3) menghindrkan diri dari pemupukan kekotoran batin. 4) merasa puas dengan keterbtasa yang ada. 5) memberikan kepuasan dan kebahagiaan pada apa yang telah dimiliki. 6) meningkatkan semangat dalam usaha. 7) memberikan rasa mudah untuk dirawat atau dibantu. 8) menimbulkan rasa suka untuk tinggal ditempat sunyi demi kemajuan batinnya.

Setelah melakukan diskriptip data penelitian, maka penulis akan melakukan analisis data tersebut dengan cara membandingkan kedua tradisi budaya orang Tionghoa dengan tradisi budaya agama Buddha.

Karena terjadi beberapa kemiripan maka penulis sajikan beberapa perayaan/ festival tradisi budaya itu berurutran sesuai dengan kejadiannya setiap tahun, seperti berikut ini:

\section{a) Pergantian Tahun ( Imlek, Chun Ciek)}

Nenek moyang mengelompokan hubungan-hubungan yang komplek dalam alam semesta menjadi saling memperkuat atau saling mengendalikan. Dalam buku tentang Keharmonisan Qi Empat Musim dengan Roh Manusia yang di sadur dari karya Kaisar Kuning/ Huang Di oleh Zhou Chuncai menyebutkan:

Keempat musim dicirikan oleh pertumbuhan dimusim semi, penguatan dimusim panas, panen dimusim gugur, dan penyimpanan dimusim dingin, yang merupakan cirri-ciri Qi keempat musim itu. Tiga bulan musim semi adalah musim pembaharuan bagi segalanya. Dengan segalanya berkembang, dunia penuh dengan kehidupan. Tiga bulan musim panas adalah masa masa pertumbuhan yang semarak. Qi langit turun dan Qi bumi naik. Segalanya berubah dengan terjadinya hubungan intim di antara kedua itu. Tiga bulan musim gugur adalah musim menuai. Cuacanya semakin dingin karena angina bertiup semakin kencang. Qi bumi bersih dan segalanya berubah warna. Tiga bulan musim dingin adalah musim untuk menutup dan menyimpan, dimana sungai- 
sungai membeku dan tanah retak-retak. (Zhou Chuncai, 2002 : 41)

Setiap pergantian tahun penanggalan Imlek (Im = bulan, Lek = kalender/ penggalan $)$ dirayakan sebagai CHUN CIEK/ festival musim semi oleh masyarakat Tiongkok dari dulu hingga kini dan sudah mengakar menjadi tradisi. Hal ini dapat dipahami bahwa masyarakat Tiongkok tradisional dahulunya adalah masyarakat agraris yang hidup sebagai petani. Selama musim dingin dalam cuaca yang ekstrim tidak bisa keladang, semua berkumpul dirumah sambil menghangatkan diri ditungku perapian (Bui Lu/ Ui Low).

Datangnya musim semi memberi harapan dan semangat baru bagi para petani pergi ke ladang untuk menyemai. Bagi masyarakat tradisional dahulu CHUN CIEK adalah kebahagian dan kegembiraan yang harus dirayakan hingga sekarang sekalipun saat ini kita sudah tidak bertani lagi.

Di Indonesia karena tidak ada musim semi, masyarakat Tionghoa membuat replika Mei Hwa. Mei Hwa adalah satu-satunya bunga yang dapat bertahan di musim gugur menjelang musim semi. ImLek telah dirayakan ribuan tahun lalu sebagai makna bersyukur kepada Tuhan bahwa satu tahun telah berlalu dengan selamat dan sukses. Dalam poerayaan Imlek juga dilakukan sungkemana pada orang tua untuk meinta maaf atas perbuatan yang diperbuatnya (kui ping sen) sembahyang di kelenteng/vihara untuk meuja pencipta alam semesta atau memberi penghormatan pada Toa Pe Kong, membagikan angpao(amplop merah) padaorang tua, mereka yang belum kerja dan para kerabat.

Dominasi warna merah, bunyi-bunyian dan keramaian disebabkan konon menurut cerita dari mulut kemulut, jauh sebelum zaman Huang Ti (2698 S.M) menjelang pergantian tahun muncul sejenis binatang buas Nian Show yang selalu makan apa saja yang dijumpai. Binatang ini hibernasi/ tidur sepanjang tahun dan hanya akan bangun setahun sekali untuk mencari makan. Dari berbagai pengalaman yang ada mereka yang memakai baju merah, sedang pesta meriah dengan berbagai bunyi-bunyian selamat dari gangguan Nien Show hingga sekarang.

Terdapat beberapa tradisi budaya disekitar perayaan Imlek seperti :

- Seminggu sebelum Imlek, sembahyang mempersembahkan kue kranjang yang manis dan kenyal kepada Dewa Dapur supaya Dewa Dapur tidak banyak bicara saat menghadap Kaisar Langit.

- Tidak menyapu selama tiga hari mempunyai kepercayaan agar rejeki tidak hilang tersapu.

- Kemudian dihari ketujuh makan sayur tujuh macam mempunyai kepercayaan agar siapa saja yang memakannya memiliki indera penglihatan tajam dan jelas, sekaligus sebagai bentuk keseimbangan gisi akibat banyak makan daging selama merayakan Imlek.

\section{b) Cap Go Meh / Cang Njiat Pan, Yuan Shiau Ciek.}

Setiap tanggal 15 bulan 1 penanggalan Imlek etnis Tionghoa akan merayakan Cap Go Meh yang berarti malam kelima belas (Cap go=lima belas, Meh= malam) dialek Hokkien dan dalam dialek Hakka disebut Cang Nyiat Pan yang berarti pertengahan bulan satu atau dalam bahasa Mandarin disebut Yuan Shiau Ciek yang artinya Festival Malam bulan Satu.

Yuan Shiau Ciek salah satu Festival yang dirayakan sejak Dinasti Xie Han (206 S.M -24 M) untuk menandakan berakhirnya perayaan tahun baru. Makna Yuan Shiau Ciek secara religius para penganut Taoisme adalah untuk memperingati lahirnya Dewa Langit/ Thian Kuan. (Shang Yuan Thian Kuan). 
Versi lain yaitu pada tanggal 15 malam, bulan 1 Imlek pada Dinasti Tung Zhou (770 s.M - 256 S.M) para petanai memasang lampion-lampion untuk mengusir hama dan menakut-nakuti binatang-binatang perusak tanaman. Setiap tahun semakin banyak petani yang memasang lampion sehingga membentuk pemandangan yang indah, dan untuk menakut-nakuti binatang perusak tanaman ditambah bunyi-bunyian, bermain barongsai serta arak-arakan Tatung sebagai tolak bala dan lebih ramai.

\section{c) Sembahyang Kuburan}

Sembahyang kubur dalam tradisi Tionghoa adalah upacara tradisi yang mempunyai maksud untuk memberi makan atau sesajian kepada para leluhur yang telah meninggal dunia. Tradisi ini dilaksanakan dua kali dalam satu tahun yaitu CHING MING yang dilaksanakan bulan ketiga Imlek dan CHUNG YUAN / SHI KU yang dilaksanakan mulai tanggal 1- 15 bulan tujuh.

\section{1) Ching Ming / Ceng Beng,}

Sembahyang kuburan ini sudah ada semenjak Dinasti QIN (221 s.M -206 s.M) dan meluas pada Dinasri SHUI ( 581-618). Pada Dinasti Tang (618 - 907$)$ berkembang merata keseluruh daratan Tiongkok, bahkan dibawa merantau orang Tionghoa menyebar kemanamana. Pada masa Ching Ming dilaksanakan sesuai situasi dan kondisi setempat, nilai yang terpenting pada Ching Ming adalah $\mathrm{XAO} \mathrm{MOH}$ (membersihkan kuburan, berziarah) yang menandakan bahwa kuburan itu masih ada keturunan yang masuh hidup serta memeliharanya dan mendoakannya. Persembahan yang diberikan berupa: lilin, hio/ dupa, uang-uangan dan pakaian alam barzah, tiga jenis daging dan teh.

Dalam legenda Ching Ming adalah cara penghormatan Kaisar pada pembantunya yang setia dalam perjuangan menegagkan kerajaan yang sah. Karena sulitnya mencari makan pembantunya ini mengiris dagingnya sendiri untuk dimasak dan dipersembahkan Kaisar. Kaisar menjanjikan kedudukan dikemudian hari jika Ia berhasil. Dan setelah berhasil Kaisar menjadi sibuk mengurus kerajaan dan hiburan sehingga janji Kaisar tinggal janji. Dan sipembantu masih tetap dengan kemiskinanya. Si pembantu malu untuk menagih janji pada Kaisar dan ia malah mengasingkan diri dalam hutan dari sebuah gunung.

Suatu ketika penyair istana menghadiahkan puisi yang berisi sejarah perjuangan dan puji-pujian terhadap Kaisar. Diakhir puisi sang Kaisar teringat pada pembantunya yang setia maka mulailah Ia mencari dan membuat pengumuman agar pembantunya mau menghadap. Pembantunya merasa merawat orang tua, membantu Kaisar dan membela negri adalah suatu kuwajiban yang tak perlu di beri imbalan.

Putus asa dengan usahanya memanggil si Pembantu, Kaisar memerintahkan membakar hutan digunung itu dari ketiga sisi dan menyisakan satu sisi dengan harapan pembantunya mau keluar dari sisi yang tidak terbakar itu. Tetapi anggapan Kaisar keliru dan si pembantu tetap dalam pendiriannya, memilih mati terbakar. Ia menyembunyikan baju yang telah ditulis syair dengan darahnya dilobang sebatang pohon :

Sayatan daging untuk Baginda, ungkapan hati nan takzim

Semoga Baginda, tuanku senantiasa berhati bening

Menjadi hantu dibawah pohon takkan bersua susah

Itu lebih baik dari pada menghamba menemui Tuan

Bila dalam hati baginda ada diriku

Saat teringat akan daku, sudilah bermawas diri 
Maka hamba dialam arwahpun tiada berhati sesal

Bersih mengelola pemerintah, bersih bening selalu.

\section{(Thitayanno,bhikkhu, 2006 )}

Kaisar menyesal, Ia menangis dibawah pohon itu tetapi apa boleh buat, ibarat nasi telah menjadi bubur. Lalu ia membuat sandal terbuat dari kayu itu untuk mengenang pembantunya yang setia, dan memerintahkan untuk membangun Kuil/ Wihara ditempat itu agar Ia dapat memberikan penghormatan padanya.

\section{2) Chung Yuan/ Shi ku,}

Sembahyang kuburan ini dilakukan oleh sebagian besar etnis Tionghoa yang menganut Buddha, Taoisme, Konghucu dan lainya di tanggal 15 bulan 7. Sebagai hari terakhir penutupan sembahyang kuburan Chung Yuan dilakukan upacara sembahyang rebutan yang dinamakan Yi Lan Sen Hui (Chiong Shi Ku dialek Hakka atau Chio Si Kow dialek Tio Ciu) dan puncaknya diadakan pembakaran Jong Son (kapal simbolis) yang berisi kebutuhan pokok sehari-hari. Diadakannya acara rebutan dalam kegiatan ini bermaksud untuk membubarkan dan sekaligus menutup pesta para Roh yang telah berlangsung dan berharap dapat berkumpul tahun depan. Makna religius ( Dhamma) dari peristiwa ini adalah rasa bakti pada leluhur yang telah meninggal.

\section{d) Tradisi budaya Mandi U Shi}

Warga perantauan Tionghoa perantauan Singapura, Malaysia, Hong Kong dan Taiwan seriap tanggal 5 dan bulan 5 Imlek kalendernya pasti berwarna merah, hal itu menandai bahwa hari itu ada Ritual Tuan U Ciek dengan tradisi membuat kue Bak Cang dan mandi tengah hari U Shi/ Wu Shi.
Dalam kepercayaan Tionghoa tradisional, mandi di saat U Shi/ tengah hari akan membawa berkah dan keselamatan. Segala sifat buruk dan tabiat tidak baik biar hanyut mengikuti derasnya air yang mengalir. Dan intinya adalah saat mandi U Shi adalah untuk introspeksi dan mawas diri sehingga dapat memperbaiki kualitas hidup. Air U Shi dapat disimpan, untuk masak obat.

Kue Bak Cang (Tio Ciu, Hokkien) atau Nyuk Cung (Hakka) adalah kue yang berbentuk kerucut yang terbuat dari beras ketan pilihan, di dalamnya berisi; cincangan daging, kacang tanah, jamur kering, kau lat/ kenari, udang ebi dll. Untuk yang vegetarian kue Cang yang tawar, dimana makannya dengan gula saja.

Setelah ritual mandi U Shi ada yang menyelengarakan lomba dayung sampan naga Liung Song/ Leng Cun sambil makan Bak Cang. Acara ini dikenal dengan Ng Nyat Ciat/ Ngo Gwek Cot. Diadakannya acara ini konon terjadi dizaman Chu-Kuok dimana hidup seorang pejabat istana yang cerdi pandai dan sekaligus sastrawan terkenal bernama Chiu Yuan. Puisi-puisinya yang kritis banyak menyindir pejabat-pejabat yang korup. Mereka yang tersudutkan menyusun strategi supaya Chu Yuan dapat terusir dari istana.

Dalam pengasingannya Chu Yuan tidak mau bekerja sama dengan para pejabat yang korup, tidak dicintai rakyantya. Kehidupan istana tidak berubah banyak pejabat yang melalaikan tugas untuk kesejahteraan rakyat. Sibuk berpesta dan berfoya-foya. Ia semakin sedih dan putus asa. Tepat tanggal 5 bulan 5 tahun 278 s.M, Chu Yuan mengakiri hidupnya bunuh diri terjun kesungai Mi Lo (Mi Lo Ciang) untuk selama-lamanya. Yang tertinggal hanya kasut saja.

Karena dicintai rakyat, kematian Chu Yuan menggemparkan rakyat, belakangan Kaisar menyesal dan memerintahkan mencari 
penyair budiman tersebut. Spontan rakyat membuat kue Bak Cang dan mendayung kapal menyusuri sungai itu. Melemparkan kue Bak Cang dengan maksud supaya ikan, buaya dan binatang-binatang air makan kue itu, tidak memakan jasad dari Chu Yuan. Makna religius ( Dhamma) yang terkandung didalamnya yaitu budi baik dan pengorbanan akan dikenang sepanjang waktu.

\section{e) Legenda Kue Bulan}

Festival Kue Bulan (Cung Chiu Ciek) berlangsung pada tanggal 15 bulan 8 Imlek setiap tahun. Awal mulanya festifal Kue Bulan lebih dari 2000 tahun, yakni mulai dari zaman Warring States (Chan Kuok 476221 s.M) Cung Chiu Ciek secara harafiah adalah Festifal Pertengahan Musim Gugur. Perayaan itu awalnya hanya diseputar istana dan birokrasi saja, hal itu sehubungan dengan kepercayaan yang tersirat dalam tulisan kuna istana: Thian Tshi Chun Cau Je, Chiu Sie Yek, yang berarti musim semi Kaisar sembahyang matahari, musim gugur sembahyang bulan.

Mulai Dinasti TANG (618-907) tradisi kue bulan menyebar luas golongan elite keatas. Hal ini setelah Kaisar Thang Ming Huang bermimpi pergi kebualan, menurut legenda bulan 8 tanggal 15 malam. Saat itu Kaisar sedang berjalan-jalan ditaman istana bersama bhiksu Lo Kung Yen. Ketika memandang langit Kaisar bergumam alangkah indahnya dapat berjalan kebulan. Mendengar kalimat bernada keinginan itu bhikksu Lo Kung Yen menanggapi sembari mengarahkan tongkat saktinya kebulan dan suatu keanehan terjadi dari bulan terbentuk jembatan langit sehingga Kaisar dapat perfi kebulan.

Ia menikmati keindahan bulan yang tidak dimiliki bumi, sambil berkeliling bulan terlihat dewi-dewi yang cantik menari diiringi musik dengan syair-syair yang indah dan merdu. Kaisar yang hobi musik itu terkagum- kagum namun tiba-tiba hujan lebat, petir dn kilat bergemuruh. Kaisar berlari menghindari air hujan mencari temoat berteduh. Saat itulah ia terpeleset dan jatuh.

Rupanya Kaisar bermimpi, tetapi seperti betul-betul terjadi. Kesal berpisah dengan Dewi Bulan, segera ia menulis kembali syairsyair yang ia dengar dari nyanyian dewadewi yang cantik-cantik itu dalam karyanya berjudul" Chang Hen Ken yang artinya Lagu Kesal Sepanjang Masa.

Dinasti berikutnya yaitu dinasti SUNG (960-1279) tradisi kue bulan telah merakyat. Kaum pria diibaratkan matahari dan kaum wanita diibaratkan bulan. Dibeberapa tempat kaum lelaki tidak boleh sembahyang bulan, kalau toh boleh setelah kaum wanita.

Seiring perkembangan jaman Kue Bulan bukan hanya untuk sembahyang tetapi juga sarana berkomunikasi. Pemerintahan Tiongkok pada akhirnya dikuasai dinasti YUAN (1271-1368) dominasi suku Mongol yang kejam. Semua aktifitas rakyat dijaga oleh prajurit Mongol, rakyat tertekan dan sangat menderita maka seorang patriot bernama Chang Shi Sheng mempunyai ide memasukan pesan dalam kue bulan. Isi pesan itu adalah" Pak Yek Sek U, Cia Cia Ciu Tung Shaou" artinya bulan 8 tanggal 15,. Tiaptiap rumah bergerak serempak. Dan rencana pemberontakan dapat berjalan dengan mulus. Tiongkok kini dipimpin dinasti Ming dari suku Han (1368-1644) dengan kaisar bernama Cu Yuan Chang. Pada saat itu Tiongkok memasuki musim panen, masyarakat setempat membuat sesajian untuk Dewa Bumi (To Tie Kong) sebagai ungkapan terima kasih memperoleh hasil yang baik. Festival Kue bulan ditayakan sangat meriah sepanjang tahun seperti layaknya hari merayakan Hari Nasional.

Sewaktu Tiongkok dipimpin Kaisar Ming She Chu, ia memerintahkan membuat 
suatu tenpat yang indah dan agung khusus untuk sembahyang bulan, serta hari pemberontakan bulan 8 tanggal 15 setiap tiga tahun sekali. Kaisar sendiri yang memimpin upacara ritual bulan. Tempat iru dinamakan Cing Yuek Than Kung Yuan atau Moon Offer Park.

\section{f) Kue Onde (Siak Jan/ Tang Ceh)}

Tang-Ceh berarti musim dingin. Di Tiongkok para ibu membuat onde-onde dari ketan dan memasak lo-mie/ mi sua untuk disajikan pada suami, mertua, anak dan menantu sebagai ujud kasih sayang ibu pada keluarganya dan di indonesia dikenal sdebagai hari ibu. Festifal Kue Onde / ritual Tang Ce jatuh pada tanggal 15 bulan 9 untuk menandakan bahwa musim dingin telah tiba saatnya untuk menghangatkan diri dengan makan Kue Onde.

Terdapat sebuah legenda, seorang pemuda tabib saat meramu obat matanya terkena obat sehingga menjadi buta. Terdorong rasa belas kasihnya sang ibu mencongkel kedua matanya untuk diberikan pada putranya itu serta menyarankan membuat kue ondeonde dari ketan. Dan untuk mengenang dan membalas pengorbanan ibunya itu ia setiap tahun mempersembahkan kue onde-onde. Tradisi itu berlangsung hingga sekarang.

Budaya spiritual Buddhis yang berujud idiil dari tradisi budaya Buddhis adalah Dharma/ hukum kebenaran universal. Ecara singkat meliputi: Catur ariya saccani, Karma phala dan punarbhawa, Trilaksana dan Paticcasamuppada. Sedangkan sistem sosial, spiritual ini meliputi cara hidup para bhikkhu maupun umat awam.

\section{a) Tradisi Uposattha}

Uposatha mengandung arti masuk untuk berdiam (dalam keluhuran). Dihari Uposatha yaitu harihari bulan purnama, bulan gelap kadang-kadang diantara keduanya (bulan sabit) para bramana meninggalkan rumah dan keluarganya untuk menyucikan diri menjalani ritus Weda, sedang para pertapa memperdalam teori dan latihan mereka . Buddha Gotamapun menyetujui saran raja Bimbisara dari magada untuk menganjurkan para bhikkhu berkumpul divihara pada hari Uposatha. Buddha menggunakan hari Uposatha untuk membahas Dharma.

Buddha menjelaskan pada Wisakkha, bahwa Uposatha bagi golongan orang muliya/ ariya tidak lain adalah cara untuk membersihkan pikiran melalui cara yang benar. Melakukan perenungan pada Tiratana (Buddha, Dhamma, Sangha) sehingga timbul kegembiraan sehingga kekotoran batinpun lenyap.Ia juga merenungkan kebajikannya sendiri yang tidak ternoda, tanpa napsu dan khayalan, terpuji, yang mengarah pada kosentrasi pikiran.Ia juga merenungkan kemulian para dewa dan kebajikan para arahat.

Umat awam (upasaka-upasika) dihari Uposatha dapat tinggal seharian untuk melatih dan mempraktekan Atthangika Uposatha (Uposatha dengan delapan unsur). UpasakaUpasika memasuki hari Uposatha dengan melakukan upacara memohonan tuntunan Atthangika Uposatha kepada bhikkhu. Delapan latihan itu yaitu: 1) tidak membunuh, 2) tidak mencuri, 3) tidak melakukan hubungan kelamin, 4) tidak berdusta, 5) tidak mabuk, 6) tidak makan lebih dari tengah hari, 7)tidak mencari hiburan, tidak menggunakan wangiwangian, kosmetik dan perhiasan, 8) tidak menggunakan tempat tidur dan tempat duduk yang tinggi dan mewah. Tradisi Uposatha dilingkungan umat awam awalnya mengikuti tradisi bhikkhu 2 kali sebulan, tetapi kemudian ada yang mempraktekan 4 kali sebulan yaitu tanggal 1,8, 15 dan 23 Imlek.

Bagi para bhikkhu, tradisi Uposatha adalah berkumpul bersama membaca Patimokkha yaitu peraturan dan tata tertib bagi 
para bhikkhu maupun bhikkhuni. Pembacaan Patimokkha kebikkhuan hanya dua kali dalam sebulan yaitu bulan gelap dan bulan terang/ purnama.

Manfaat Uposatha: Buddha pernah bersabda bahwa pada hari kedelapan dan empat belas paruh bulan, para pembantu Empat Dewa Raja (catummaharajika) melanglang buana untuk melihat apakah orang-orang menjunjung orang tuanya, menghormati para pertapa, brahmana dan pemimpinnya, melaksanakan puasa, waspada danberbuat baik Di hari ke limabelas Empat Raja Dewa sendiri melanglang buana dan melaporkan temuanya pada sidang Tiga puluh tiga dewa (Tavatimsa). Apabila Uposatha dilakukan / mematuhi delapan peraturan itu hasilnya sangat besar, sangat menggetarkan kalbu. Kelak sekalipun belum merealisai Nibbana mereka akan terlahir dialam sorga yang bermacam-macam tingkatanya. Mendatangkan kebahagiaan dsiri sendiri dan orang lain. (Angutara Nikaya,I: 42)

\section{b) Tradisi Puja}

Dalam Manggala Sutta bait ke 2 berbunyi" Pujace pujaniyanng, etang manggala muttamang, memuja kepada yang patut dipuja adalah berkah utama. Yang patut dipuja yaitu Buddha, Pacceka Buddha dan arahat. Yang juga patut dihormati adalah orang tua, guru dan mereka yang lebih tua dari kita.

Tradisi Puja adalah cara yang termudah dalam menyelami Dhamma (upayakausalya). Ketika seseorang menghormati orang lain yang patut dihormati, sesungguhnya orang tersebut daopat dikatakan terhormat. Rasa hormat dapat ditunjukan pada Buddha, para Arahat, Para Bhikkhu, Orang tua, guru dan pada siapa saja yang lebih tua, terlebih bagi mereka yang menjalankan sila. Seseorang memberikan penghormatan pada mereka karena prilakunya. Dengan menghormati mereka, ia telah menghargai dirinya sendiri. Hal ini menunjukan tekad bahwa ia bertekad mengembangkan nilai-nilai kebajikan sebagaimana yang dilakukan oleh orang yang dihormati, hal ini sekaligus telah membangun kepribadian seseorang.

Ketika kita menghormati seseorang, kita harus menyadari bahwa orang yang kita hormati telah membantu kita dalam meningkatkan kualitas diri kita sendiri, belajar rendah hati. Karena kebodohan dan kesombongan seseorang tidak mau menghormati pada mereka yang layak dihormati. Dengan bersikap demikian justru telah menanam benih penderitaan di kemudian hari.

Buddha dan arahat adalah orang yang paling patut dihormati. Kita dapat mnghormati mereka dengan berbagai cara, salah satunya adalah memuja dan mengagumiNya. Memberikan penghormatan pada orang yang telah mencapai penceragan lebih besar kepuasannya daripada menjadi raja seluruh jJambudvipa. Dalam tataran duniawi seseorang harus menghormati orang tuanya, gurunya atau orang yang lebih tua darinya untuk melatih batin yang luhur.

\section{c) Tradisi Waisak}

Sebelum mepelajari hari-hari besar agama Buddha dan tradisinya, ada baiknya kita mengenal nama-nama bulan dalam bahasa Pali/ Sansekerta, karena hari-hari besar itu diadakan sesuai nama bulanya. Bulan 1 (Maggasira/ Mrgasirsa), bulan 2 (Phussa/ Pausa), bulan 3 (Magha/Magha), bulan 4 (Phagguna/Palguna), bulan 5 (Citta/ Chaitra), bulan 6 (Vesakha/ Vaisakha), bulan 7 (Jettha/ Jyaistha), bulan 8 (Asalha/ Asadha), bulan 9 (Savana/Sravana), bulan 10 (Bhaddapada/ Bhadrapada), bulan 11 (Assayuja/ Asvayuja), bulan 12 (Kattika/ Kartika). 
Tradisi Waisak adalah upaca ritual mengenang tiga peristiwa berkaitan dengan kehidupan Buddha yang bertepatan dengan bulan Vesakha. Dimana Bodhisatva lahir sebagai Sidharta di Tama Lumbini pada purnama sidhi bulan Vesakha, tahun 623 s.M, Peristiwa kedua yaitu pettapa Siharta mencapai kesempuraan (jadi Buddha) di Buddhagaya pada tahun 588 s.M dan ketiga adalah Buddha Gotama wafat/ parinibbana, di Kusinara, pada tahun 543 s.M.

Makna religius dalam perayaan Waisak ini adalah: 1) terlahir dengan penuh kemuliaan, seperti terlahir sebagai anak raja yang sehat,tampan dan serba kecukupan adalah berkat kesempurnaan paramita/ kebajikan yang telah dipraktekan ribuan kali kelahiran.

2) Untuk mendapatkan kemakmuran/ kesuksesan perlu usaha yang gigih, ulet san pantang menyerah, 3) Kesempurnaan sebagai manusia adalah berguna bagi diri sendiri dan makluk lain.

\section{d) Tradisi Asadha}

Dua bualan setelah purnama Waisak, umat Buddha merayakan Asadha. Asadha adalah hari Dhamma, karena memperingati pembabaran Dhamma yang pertama kali. Di taman Russa Iasipatana, Sarnat, dekat Benares, pada musim panas (Gimha) Buddha menyampaikan kotbah pertama yang dikenal dengan Dhammacakkapavattana Sutta kepada lima orang pertapa. Mereka adalah Kondana, Badiya, Vappa, Asaji dan Mahanama yang menempuh cara pertapa yang eksterm. Kelima pertapa itu pada akhirnya memahami Dhamma yang di ajarkan Buddha Gotama dan untuk selanjutnya ditahbiskan menjadi bhikkhu. Sejak sasat itulah terbentuk Ariya Sangha.

Kondana berhasil menembus ajaran tentang Catur Ariya Saccani menjadi arahat, dan yang lain menyusul sesuai dengan tingkat perkembangan batinnya. Kondana mencapai kesucian pertama kali karena, konon pada kehiupan lampaunya, buah mangga hasil panen pertama kalinya didanakan pada para pertapa, bramana dan tetangga. Sebagai hasilnya ia mencapai kesucian yang pertama kalinya.

Tradisi perayaan Asadha ini berlangsung antara Jettha - Asalha (Juni-Juli ) setiap tahun. Makna religius dalam perayaan ini adalah Dhamma telah dibabarkan, kesempatan memperoleh kesucian terbuka lebar. Jangan sia-siakan kehidupan ini dengan hal-hal yang tidak bermanfaat.

\section{e) Tradisi Katina}

Setelah hari pertama Asadha para bhikkhu memasuki masa Vasssa atau musim hujan di India Utara. Selama tiga bulan para bhikkhu tidak melakukan perjananan kemanamana dengan maksud agar tidak menginjak tunas-tunas tanaman, menginjak seranggaseranga kecil dan yang bisa mengganggu kehidupan lainnya. Para bhikkhu melakukan penyepian di Wihara dan mematuhi peraturan Vassa. Para bhikkhu masih diperbolehkan melakukan perjalanan untuk memenuhi kewajibannya asal tidak melebihi 7 hari.

Selesai masa Vasssa, di hari purnama bulan Asvayuja (Oktober) dilaksanakan Upacara Pavarana. Pada masa ini mereka melakukan penyeucian (Parisudhi) dengan cara mengakui kesalahan menerima kritik, saran dan membaca Patimokha.

Hari berikutnya, hari ke 16 dan seterusnya hingga bulan Kattika dapat dipilih salah satu hari untuk menyelengarakan upacara Kathina. Jadi Kathina tidak hanya berlangsung satu hari saja. Pada hari Kathina umat awam/ para perumah tangga memberikan empat kebutuhan pokok bhikkhu; jubah, makanan, pakaian dan obat-obatan. Dana pada bhikkhu sangha adalah dana yang tepat, terlebih pada 
orang yang baru keluar dari samapati, dana itu akan berbuah pada kehidupan ini juga.

Upacara Kathina dapat dilaksanakan jika sedikitnya terdapat 5 orang bhikkhu dan jika hanya 1 orang bhikkhu dapat dilakukan dana jubah bhikkhu. Tradisi dana jubah ini berlangsung sebagai ujud rasa bhakti pada para bhikkhu sangha. Upacara mempersembahkan jubah ini dihubungkan dengan riwayat 33 bhikkhu dari Pava yang hendak menemui Buddha Gotama. Setelah melewati Vassa, hujan juga belum berhenti. Mereka menerobos lebatnya hujan sehingga ketika menghadap Buddha jubah para bhikkhu robek compang -camping. Buddha mengijinkan para bhikkhu menerima persembahan jubah dan sejak saat itu hingga kini Tradisi Persembahan Jubah Kathina berlangsung.

\section{f) Tradisi Maghapuja}

$$
\text { Magha puja memperingati }
$$
berkumpulnya 1250 bhikkhu arahat. Mereka ditahbiskan sendiri oleh Buddha (Ehi Bhikkhu upasampada). Para bhikkhu itu memiliki 6 abhinna/ kekuatan batin sehingga mereka berkumpul tanpa diundang atau membuat janji untuk menghadap Buddha. Pertemuan itu berlangsung di Taman Tupai, VeluvanaArama, Rajagaha saat musim dingin (Sisira) dibulan Magha/ Pebruari.

Pada kesempatan ini Buddha membabarkan Ovada-Patimokkha, inti sari ajaran Buddha. Perayaan Maghapuja bertepatan dengan Cap Go Meh. Tetapi Magha puja bukan Cap Go Meh, karena Cap Go Meh adalah pentupan perayaan tahun baru.

\section{g) Tradisi ulambana}

Pada tanggal 15 bulan 7 penanggalan Imlek, umat Buddha menyelengarakan upacara Ullambana. Menurut cacatan sejarah, semula orang-orang menyelenggarakan upacara ini dengan persembahan yang ditujukan pada Buddha dan Sangha atas nama tujuh generasi leluhur. Oada jaman dinasti Tang terdapat seorang bhikksu tantrayana bernama Amoghavajra menyesuaikab dengan kepercayaan tradisi setempat. Dan mulai saat itu Upacara Ullambana ditujukan pada arwah yangtelah nebinggal.

Upacara Ullambana dilatar belakangi dari gagasan dari ullambana patra sutra. Moggalana setelah mencapai kesempurnaan, mampu melihat kelahiran ibunya almarhum yang terlahir menderita sebagai hantu/ petta. Dengan kekuatanya yang sakti ia menolong ibunya yang menderita itu, namun selalu tidak berhasil, Mendapat petunjuk Buddha, untuk menolong ibunya dengan kekuatan anggota sangha yang suci melakukan pelimpahan jasa, maka ibunya dapat ditolong.

\section{h) Imlek -Buddhis Mahayana}

Masyarakat Tionghoa tradisional atau Buddhisme Mahayana percaya bahwa tanggal 1 bulan 1 Imlek adalah kelahiran Maitreya Bodhisatva. Sebagian percaya bahwa Bhiksu Pu Tai yang hidup pada akhir dinati TANG (abad ke 10) adalah manifestasi dari Bodhisatva Maitreya. Menurut Cakkavati Sihananda Sutta, Maitreya adalah Buddha yang akan datang di dunia ini sesudah suatu masa pedang (satthantarakappa) atau zaman edan berakhir.

Puja bakti yang ditunjukan pada Bodhisatva Mahasatva Maitreyaa adalah untuk menumbuhkan sifat cinta kasih dan belas kasih (Maitri-Karuna), seperti yang dikembangkan Bodhisatva Maitreya.

\section{i) Tradisi Budaya Meditasi}

Tradisi Budaya Meditasi merupaka ciri utama dalam Buddhisme. Tradisi ini menekankan latihan kewaspadaan setiap saat, baik saat berjalan, duduk, bekerja ataupun berbicara. Saat seseorang bekerja 
dengan kosentrasi ia telah mengembangkan kewaspadaan. Duduk rilek dengan mengamati obyek nama-rupa dari jasmani atau semua aktifitas jasmani rohani tanpa terputus adalah salah satu menlatih Vipasssana Bhavana. Meditasi ini akan memperikan pencerahan spiritual.

Duduk rileks menggunakan obyek yang dipilih dengan cermat adalah salah satu meditasi Samatha Bhavana. Meditasi ini akan memberikan ketenangan hidup. Manfaat Samatha, selain memperoleh ketenangan juga beberapa yang bersifat gaib.

Tentu terjadi kesamaan dan peerbedaan sebagai ciri khas sudut pandang dari kedua faham itu. Hal itu dapat dilihat dari hasil perbandingan berikut ini.

a. Persamaan

\begin{tabular}{|c|c|}
\hline Tradisi budaya Tionghoa & Agama Buddha \\
\hline $\begin{array}{l}\text { 1. Sarana Ritual: lilin, } \\
\text { hio/ dup /kemenyan, } \\
\text { buah, bunga, air, } \\
\text { sarana membuat } \\
\text { obat. } \\
\text { 2. Menjunjung rasa } \\
\text { bakti pada leluhur. } \\
\text { 3. Ingin mencapai } \\
\text { k e s e m p u r n a a n, } \\
\text { sebagai dewa atau } \\
\text { malaikat } \\
\text { K e s e m p u n a a n } \\
\text { prilaku }\end{array}$ & $\begin{array}{l}\text { 1. Sarana Ritual: lilin, } \\
\text { hio/ dupa, buah, } \\
\text { bunga, air, obat- } \\
\text { obatan, makanan } \\
\text { 2. Menjunjung rasa } \\
\text { bakti pada leluhur } \\
\text { 3. Ingin mencapai } \\
\text { kesempurnaan, arahat } \\
\text { 4. K e s e m p u n a a n } \\
\text { prilaku }\end{array}$ \\
\hline
\end{tabular}

b. Perbedaan

Berbedaan mendasar tradisi budaya orang Tionghoa dan tradisi agama Buddha yaitu

\begin{tabular}{|c|c|}
\hline Tradisi budaya Tionghoa & Tradisi agama Buddha \\
\hline 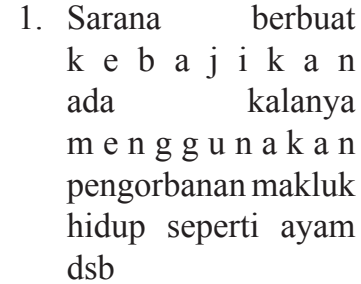 & $\begin{array}{l}\text { 1. Dalam tradisi } \\
\text { Buddha tidak ada } \\
\text { makluk hidup yang } \\
\text { dikorbankan. }\end{array}$ \\
\hline
\end{tabular}

2. Ada kalanya masih mempertontonkan kekuatan gaib untuk tujuan-tujuan tertentu yang tidak mengarah pada kesucian

3. Menjadi adalah Dewa tujuan orang Tionghoa tradisional, karena $\mathrm{m}$ e $\mathrm{n} \mathrm{g}$ a $\mathrm{n} \mathrm{g} \mathrm{g}$ a $\mathrm{p}$ menjadi Dewa dapat hidup abadi.

4. Imlek identik dengan hari raya agama tradisional Tionghoa bahkan ada yang mengklaim sebagai hari raya Konghucu

2. Tidak

ada $\mathrm{p}$ e r t u n j u k a n kekuatan gaib/ keajaiban, hal itu justru mempertebal keegoisan. Keajaiban dalam Dhamma yaitu dapat memahami kebenaran apa adanya.

3. Menjadi Dewa bukan tujuan utama, karena masih akan mengalami kelahiran kembali. Keabadian dicapai Umat Buddha dengan mencapai kesucian araht.

4. Hari raya dalam agama Buddha mempunyai latar belakang relegius yang dapat mengarah pada kesucian

Hasil interpretasi peneliti diperoleh data sebagai berikut:

1. Agama adalah segenap kepercayaan (kepada Tuhan, Dewa dan sebagainya) serta dengan ajaran kebaktian dan kewajiban-kewajiban yang bertalian dengan kepercayaan itu; misalnya Islam; - Buddha; - Kristen. Agama didefinisikan sebagai adat dan kebiasaan atau tradisi yang digunakan manusia untuk berkomunikasi dengan roh-roh, oleh karena itu agama adalah sebagian dari budaya. Sedangkan Budaya adalah cara hidup suatu pendduduk/ kelompok dalam memenuhi kebutuhan-kebutuhannya sebagai manusia.

2. Agama Buddha adalah ajaran kebenaran (Dhamma/Dharma) yang diajarkan oleh Buddha Sakyamuni. Agama Buddha adalah jalan hidup yang benar untuk kedamaian dan kebahagiaan semua makluk hidup. Buddhime merupakan suatu metode untuk lepas dari kesengsaraan dan menemukan pembebasan. Ajaran Sang 
Budddha tidak terbatas pada satu bangsa atau ras. Ajaran ini juga bukanlah suatu syahadat atau iman semesta. Ini adalah ajaran untuk seluruh alam semesta. Ini adalah ajaran untuk sepanjang masa. Tujuannya adalah pelayanan yang tidak egois, niat baik, kedamaian, keselamatan, dan pembebasan dari penderitaan.

3. Dengan demikian menurut agama Buddha, Tradisi Budaya adalah berfungsi sebagai ornamen yang memperindah agama sehingga menarik bagi masyarakat.

4. Orang Tionghoa dapat mengikuti tradisi budaya yang telah turun temurun walaupun sama sekali tidak memiliki nilai-nilai religius, asalkan dalam pelaksanaannya tidak mengatas namakan agama tertentu apa lagi agama Buddha.

5. Buddhisme sangat terbuka terhadap berbagai adat tradisi, budaya yang mempunyainilai-nilai unversal, membawa kemajuan batin, kebahagiaan dan kesejahteraan seperti: perikemanusiaan (humanisme), patriotisme, kerelaan, kerendahan hati dll. Dengan Tradisi Budaya dalam pandangan agama buddha dapat memberi bantuan psychologis bagi beberapa orang sesuai tingkat spiritualnya.

6. Banyaknya ritual pada Tradisi Tionghoa lebih dilatar belakangi sebagai rasa bakti yang tulus akan pengabdian dan dedikasi yang tinggi akan sikap melayani.

7. Terdapat korelasi yang saling mempengaruhi dia antara tradisi Tionghoa dan agama Buddha.

\section{Kesimpulan}

Dari Penelitian yang telah dilakukan diperoleh kesimpulan bahwa terdapat persamaan dan perbedaan dari budaya orang tionghoa dengan agama buddha diantaranya dari sarana ritual yang menggunakan lilin, hio, buah, air, bunga, sarana membuat obat, makanan. Persamaan kedua yaitu menjunjung rasa bakti pada leluhur, persamaan ketiga ingin mencapai kesempurnaan dalam berperilaku serta bersikap dan ingin mencapai kesempurnaan jiwa seperti dewa dewi atau arahat. Perbedaan antara tradisi orang tionghoa dengan agama buddha yaitu pertama dalam tradisi orang tionghoa menggunakan pengorbanan makhluk hidup seperti ayam sedangkan dalam agama buddha tidak mengorbankan makhluk hidup, kedua dalam tradisi tionghoa mempertontonkan kekuatan gaib untuk tujuan tertenrtu tidak mengarah pada kesucian sedangkan dalam agama buddha tidak ada pertunjukkan kekuatan gaib, perbedaan ketiga orang tionghoa tradisional memiliki tujuan menjadi dewa sedangkan dalam agama buddha dewa bukan menjadi tujuan utama, perbedaan keempat yaitu imlek identik sebagai hari raya agama tradisional tionghoa sedangkan dalam agama buddha hari raya mempunyai latar belakang religius yang dapat mengarah pada kesucian.

\section{Daftar Pustaka}

Anggawati, Lanny dan Cintiawati, Wena. (2001). Petikan Aïguttara Nikàya 1. Klaten: Wisma Meditasi dan Pelatihan Dhammaguna

Anggawati, Lanny dan Cintiawati, Wena. (2002). Petikan Milinda Pañha. Klaten: Wisma Meditasi Dhammaguna.

Anggawati, Lanny dan Cintiawati, Wena. (2006). Khuddakapàñha 2. Klaten: Vihāra Bodhivamsa dan Wisma Dhammaguna

Asali, x.f. (2008). Aneka Budaya Tionghoa Kaimantan Barat,Pontianak, Muare Public Relation

Buletin Tridharma. (2001). Edisi 03/xx/VIII

Dawson, Raymond. Kong $\mathrm{Hu} \mathrm{Cu}$ (1992),

Penata Budaya Kerajaan Langit. 
Jakarta: PT. Pustaka Utama Grafiti.

Dhammananda, Sri. (2002) Keyakinan Umat Buddha. Jakarta: Yayasan Penerbit Karaniya.

Goey Tek Jong. (2005) Paritta Mantra dan Nama Buddhis, Sri Manggala

Gunawa, Adi. (2005). Hipnosis: seni berkomunikasi bawah sadar, Jakarta, Gramedia Pustaka Utama

Jusuf, Tedy. (2000). Sekilas Budaya Tionghoa di Indonesia. Jakarta: PT. Bhuana Ilmu Populer - Kelompok Gramedia.

Lian, Kai kuaok. (1998). Chien Chi/ Festival Tradisi Budaya Tionghoa, Shanghai, China

Mukti, Wijaya Krishnanda. (2003). Wacana Buddha Dharma, Jakarta, Yayasan Dharma Pembangunan

Ñānamoli, Bhikkhu. (1978). The Minor Readings (Khuddakapàñha). London: The Pāli Text Society.
Narada. (1995). Sang Buddha dan Ajaranajaran-Nya bagian 1. Jakarta: Yayasan Dhammadipa Arama.

Sangha Theravada Indonesia. (1989). Parita Suci, Jakarta, Yayasan Dhammadipa Arama

Sarada, Weragoda, Ven. (1997). terj.Triandy,F. Yakob, ir Maha Manggala Sutta, Jakarta, Dhammacaka Jaya.

Su Si (Kitab Yang Empat). (1970). Majelis Tinggi Agama Buddha Konghucu (MATAKIN).

Taipeh, Republik of China

Wowor, Cornelis. (2004). Pandangan Social agama Buddha, Jakarta, CV.Nitra Kencana Buana.

Yuan Bing Ling. (2000). Chinesse Demokraties, Universiteit Leiden Nederlands 